\title{
Process and barriers to organ donation and causes of brain death in northeast of Iran
}

\author{
Abdollah Bahrami ${ }^{1}$, Ebrahim Khaleghi ${ }^{2}$, Ali Khorsand Vakilzadeh ${ }^{3}$, Monavar Afzalaghaee ${ }^{4}$
}

\footnotetext{
${ }^{1}$ Department of Internal Medicine, Faculty of Medicine, Mashhad University of Medical Sciences, Mashhad, Iran

${ }^{2}$ Department of Organ Transplant, School of Medicine, Mashhad University of Medical Sciences, Mashhad, Iran

${ }^{3}$ Department of Complementary and Chines Medicine, School of Persian and Complementary Medicine, Mashhad University of Medical Sciences, Mashhad, Iran

${ }^{4}$ School of Health, Social Determinant of Health Research Center, Mashhad University of Medical Sciences, Mashhad, Iran
}

\section{Type of article: Original}

\begin{abstract}
Introduction: Organ transplantation is the treatment of choice for some diseases. However, the need for cadaveric organ donation has either plateaued or is on a decreasing trend in some countries, especially in developed ones. In this study, we aimed to identify the barriers to organ donation in brain dead patients, who were referred to the organ procurement organizations (OPO) in northeast Iran.

Methods: In this cross-sectional study during 2006 to 2013, data were collected from medical records of brain dead patients. Demographic information, cause of brain death, the process of obtaining informed consent, and the reasons for declining organ donation were obtained from the OPO records. The data were analyzed using chisquare test by SPSS 13 software.

Results: Of 1034 brain dead patients, 751 cases (72.6\%) were eligible for organ donation, and, ultimately, 344 cases underwent organ donation. The rate of organ donation increased during the course of the study; medical and legal reasons as well as family refusal to authorize donation were the main barriers to the process.

Conclusion: Based on the pattern of mortality, the need for living donors in developing countries, such as Iran and other countries in the Mediterranean region, can be reduced by improving the quality of healthcare, efficient identification of brain death, and obtaining consent with appropriate strategies.
\end{abstract}

Keywords: Brain death, Organ donation, Organ transplant

\section{Introduction}

The rate of end-stage failure of several vital organs (e.g., kidneys, liver, heart, and lungs) is increasing expeditiously due to scientific advancements and the ability to sustain brain dead patients over a long period of time (1). Organ transplantation is known as the treatment of choice for patients with advanced organ failure (2). Annually, more than 100,000 solid organ transplantations are performed worldwide, more than $50 \%$ of which are renal transplantation (3). Statistical analyses showed that the rate of organ failure is increasing faster than the sources for organ donation, and the imbalance between supply and demand has resulted in long transplant waiting lists (1). Depending on the types of required organ, approximately $10 \%-25 \%$ of patients expire while awaiting transplant (4). Given the medical and legal barriers to living donors, the use of cadaveric organ donation (brain dead patients) as a treatment method is on the rise across the world; however, this growing trend is not in proportion with organ demand $(5,6)$. The rate of cadaveric organ donation is diverse in various parts of the world. Nowadays, the rate of cadaveric organ donation is $19.4 \%, 69.5 \%, 63.1 \%, 16.6 \%$, and $60.9 \%$ in the Middle East, Europe, America, East Asia, and Australia, respectively (7). As previously mentioned, the highest rate of cadaveric organ donation belongs to European countries, among which Croatia, with over 53.8 per million populations (pmp), Spain (47.5 pmp), and Estonia (43.9 pmp) are ranked first to third regarding the use of cadaveric organ donation (8). Iran is one of the industrious

\section{Corresponding author:}

Assistant Professor Dr. Monavar Afzalaghaee, Mashhad University of Medical Sciences, Mashhad, Islamic Republic Of Iran. Tel: +985138515117, Email: AfzalaghaeeM1@mums.ac.ir

Received: June 07, 2016, Accepted: September 01, 2016, Published: February 2017

iThenticate screening: August 13, 2016, English editing: September 21, 2016, Quality control: December 12, 2016

(C) 2017 The Authors. This is an open access article under the terms of the Creative Commons Attribution-NonCommercialNoDerivs License, which permits use and distribution in any medium, provided the original work is properly cited, the use is non-commercial and no modifications or adaptations are made. 
countries regarding organ transplantation; in addition, it is one of the 30 high-demand countries with high rates of renal transplantation (9). Currently, the rate of renal transplantation is $12 \mathrm{pmp}$ in Iran, and it is ranked 36 in the world, after Turkey, Saudi Arabia, Bahrain, and Qatar (8). In Iran, due to the high rate of organ transplantation and ranking first in the region regarding cadaveric organ donation, living donor transplantation is tried to be replaced with cadaveric organ donation. For this purpose, legislation on cadaveric organ donation was approved by the parliament in 2000. Moreover, prominent clergies announced their agreement with cadaveric organ donation (10). This study aimed to identify the barriers to organ donation in brain dead patients, referred to organ procurement organizations (OPO) of Mashhad University of Medical Sciences, Mashhad, Iran.

\section{Material and Methods}

\subsection{Research design and setting}

In this cross-sectional study, data were gathered from medical records of patients who were referred to OPOs of five hospitals affiliated with the Mashhad University of Medical Sciences, Mashhad, Iran, during 2006-2013. Approximately, $8.6 \%$ of the brain dead patients were referred to private hospitals, and the rest were referred to governmental hospitals.

\subsection{Data collection and analysis}

Demographic information such as name, age, gender, time interval between admission and brain death, place of residence, religion, admission date, reason for family's refusal to organ donation, and cause of brain death were recorded. The causes of brain death were categorized as follows: motor vehicle traumas, cerebral hemorrhages (nontraumatic cases), brain tumors, and others (including drug poisoning, except for drugs affecting the central nervous system, convulsion, and anoxia). The patients were divided into three groups as follows: 1) brain dead patients not eligible for organ donation due to medical reasons such as age above 65 years, sepsis, and chronic infectious diseases (e.g., hepatitis B or C, and human immunodeficiency virus); 2) brain dead patients who were medically eligible for donation, but organ donation was prohibited due to legal reasons such as medical malpractice, lack of access to legal heirs, or private prosecution; 3) potential donors without legal prohibition and with at least one organ appropriate for transplantation. Families were consulted for obtaining consent to organ donation. If they consented to organ donation, the brain dead patient was placed under conservative treatment. If the patient survived until completing consultation with patient's family and obtaining consent to organ donation, organs were harvested. Based on interviews with experts, reasons for declining organ donation were identified and evaluated separately, and the data were analyzed using chi-square test by SPSS version 13 (SPSS Inc. Chicago, Illinois, USA).

\section{Results}

All the studied patients were Muslims; the mean age of the patients was $30.25 \pm 16.52$ years. The occurrence of brain death in the age group of $\leq 18$ years decreased from 14\% (39 people) in 2006 to $11.2 \%$ (30 people) in 2013. The cardinal causes of brain death were head trauma (667 patients [65.2\%]), ischemic cerebrovascular accident (CVA) (174 patients [17\%]), anoxia (91 patients [8.8\%]), brain tumor (67 patients [6.6\%]) and other cause (25 patients [2.4\%]). The majority (69.8\%) of the brain dead patients was male, and sex ratio did not change significantly during the study. During 2006-2013, brain death was not confirmed in eight patients among 1042 declared cases of brain death, who were excluded from the study; finally, in 1034 patients, brain death was confirmed. The number of brain dead patients, referred to OPOs, increased from 129 patients in 2006 to 135 in 2013. In 2009, only 104 brain dead patients were referred to OPOs, which was the lowest number of annual brain death during the study. The range of hospital stay before brain death was 1-48 days. The mean interval between admission and brain death was 4.2 \pm 5.06 days during the current study. The majority $(69.8 \%)$ of the brain dead patients was male, and sex ratio did not change significantly during the study. In total, the rate of brain death due to trauma decreased from $62 \%$ in 2006 to $57 \%$ in 2013 (Table 1). Of the confirmed cases of brain death, $212(20.5 \%)$ were medically ineligible for donation, and $86(40.6 \%)$ and $28(13.2 \%)$ of whom had uncorrectable hypotension and infection, respectively. Moreover, 39 (18.4\%) patients were aged more than 65 years. The other medical reason for declining organ donation was multiorgan failure, which was observed in $59(29.8 \%)$ patients. During the study, the number of patients who were not medically approved for donation diminished from 43 in 2006 to 17 patients in 2013. Organ donation was not performed in 89 (8.4\%) patients due to legal reasons. More specifically, the organs of 38 (42.7\%), 28 (32.2\%), 19 $(21.3 \%)$, and 4 (4.6\%) of the patients were not donated because of unavailability of legal heirs, having nationality of other countries, private prosecution, and medical malpractice, respectively. In these cases, no interviews were conducted with patients' families or next of kin for organ donation. The initial interview was performed with families of 733 patients with legal heirs in the third group. During the interview, $82(11.2 \%)$ patients were excluded from the list of potential donors due to cardiac arrest. Organ donation was carried out in 344 (52.8\%) patients, while 
organ donation was not authorized for the rest of the cases. The rate of organ donation increased during the study; that is, the rate of organ donation was 119 and 225 cases before and after 2008, respectively. The rate of organ donation refusal by the families reduced during the study. The most important reasons for families' refusal were not accepting the brain death $(20.1 \%)$, fear of organ donation to non-coreligionists $(8.1 \%)$, fear of organ trafficking $(5.5 \%)$, belief in miracles $(12 \%)$, fear of corpse mutilation or deformation $(4 \%)$, adverse reaction of others $(2 \%)$, asking for money (3\%), and view of clergies (3\%); no reason was spelt out by $42.2 \%$ of the families. The cardinal reasons for declining organ donation in the studied cases were fear of organ donation to non-coreligionists and not accepting brain death, respectively. In case of declining organ donation, it was refused by all heirs in $81.3 \%$ ( 253 families) of the cases. Among the legal heirs, the strongest opposition to organ donation was observed in the patients' mothers; mothers were the only persons who refused organ donation in 45 cases (14\%), which reduced from $10 \%$ to $1 \%$ by the end of the study.

Table 1. Information of patient's studies

\begin{tabular}{|c|c|c|c|c|c|c|c|c|c|c|}
\hline \multirow{2}{*}{\multicolumn{2}{|c|}{ Variable }} & \multicolumn{8}{|l|}{ Year } & \multirow[t]{2}{*}{ Total } \\
\hline & & 2006 & 2007 & 2008 & 2009 & 2010 & 2011 & 2012 & 2013 & \\
\hline \multicolumn{2}{|l|}{ Potential donor } & 129 & 138 & 128 & 133 & 104 & 120 & 147 & 135 & 1034 \\
\hline \multicolumn{2}{|l|}{ Realize donor } & 24 & 31 & 27 & 37 & 46 & 39 & 68 & 72 & 344 \\
\hline \multicolumn{2}{|l|}{ Not realized donor } & 105 & 107 & 101 & 96 & 58 & 81 & 79 & 63 & 690 \\
\hline \multicolumn{2}{|c|}{ Medical contraindication } & 43 & 40 & 29 & 24 & 20 & 25 & 14 & 17 & 212 \\
\hline \multicolumn{2}{|c|}{ Cardiac arrest } & 8 & 23 & 16 & 6 & 7 & 11 & 7 & 4 & 82 \\
\hline \multicolumn{2}{|l|}{ Declining donation } & 45 & 28 & 36 & 51 & 27 & 42 & 46 & 32 & 307 \\
\hline \multicolumn{2}{|l|}{ Legal prohibition } & 9 & 16 & 20 & 15 & 4 & 3 & 12 & 10 & 89 \\
\hline \multirow{3}{*}{\multicolumn{2}{|c|}{ Age group of potential donor (year) }} & 39 & 37 & 38 & 40 & 21 & 29 & 33 & 30 & 267 \\
\hline & & 84 & 98 & 88 & 91 & 78 & 87 & 111 & 101 & 738 \\
\hline & & 5 & 1 & 2 & 2 & 5 & 3 & 3 & 3 & 24 \\
\hline \multirow{3}{*}{\multicolumn{2}{|c|}{ Age group of realized donor (year) }} & 9 & 7 & 8 & 12 & 8 & 8 & 16 & 19 & 87 \\
\hline & & 15 & 24 & 19 & 25 & 38 & 31 & 51 & 53 & 256 \\
\hline & & 0 & 0 & 0 & 0 & 0 & 0 & 1 & 0 & 1 \\
\hline \multirow{3}{*}{\multicolumn{2}{|c|}{ Age group of nonrealized donor (year) }} & 30 & 30 & 30 & 28 & 13 & 21 & 17 & 11 & 180 \\
\hline & & 69 & 74 & 69 & 66 & 40 & 56 & 60 & 48 & 482 \\
\hline & & 1 & 2 & 2 & 5 & 3 & 2 & 3 & 23 & 23 \\
\hline \multirow{5}{*}{$\begin{array}{l}\text { Cause of brain } \\
\text { death in potential } \\
\text { donor }\end{array}$} & Head trauma & 81 & 97 & 93 & 91 & 75 & 79 & 84 & 77 & 677 \\
\hline & $\begin{array}{l}\text { Cerebrovascular } \\
\text { accident (CVA) }\end{array}$ & 26 & 29 & 12 & 16 & 16 & 11 & 32 & 32 & 174 \\
\hline & Brain tumor & 6 & 6 & 7 & 11 & 5 & 14 & 9 & 9 & 67 \\
\hline & Anoxia & 11 & 6 & 14 & 12 & 6 & 12 & 16 & 14 & 91 \\
\hline & Others & 5 & 0 & 2 & 3 & 2 & 4 & 6 & 3 & 25 \\
\hline \multirow{5}{*}{$\begin{array}{l}\text { Cause of } \\
\text { brain death in } \\
\text { realized donor }\end{array}$} & Head trauma & 18 & 26 & 22 & 23 & 39 & 22 & 34 & 45 & 229 \\
\hline & CVA & 3 & 4 & 1 & 6 & 5 & 6 & 19 & 12 & 56 \\
\hline & Brain tumor & 1 & 1 & 1 & 3 & 2 & 6 & 4 & 4 & 22 \\
\hline & Anoxia & 1 & 0 & 3 & 5 & 0 & 4 & 7 & 10 & 30 \\
\hline & Others & 1 & 0 & 0 & 0 & 0 & 1 & 4 & 1 & 7 \\
\hline \multirow{5}{*}{$\begin{array}{l}\text { Cause of } \\
\text { brain death in } \\
\text { nonrealized donor }\end{array}$} & Head trauma & 63 & 71 & 71 & 68 & 36 & 57 & 50 & 32 & 448 \\
\hline & CVA & 23 & 25 & 11 & 10 & 11 & 5 & 13 & 20 & 118 \\
\hline & Brain tumor & 5 & 5 & 6 & 8 & 3 & 8 & 5 & 5 & 45 \\
\hline & Anoxia & 10 & 6 & 11 & 7 & 6 & 8 & 9 & 4 & 61 \\
\hline & Others & 4 & 0 & 2 & 3 & 2 & 3 & 2 & 2 & 18 \\
\hline \multicolumn{2}{|c|}{ Number of harvested organs } & 72.00 & 102.00 & 125.00 & 163 & 184 & 158 & 272 & 284 & 1807 \\
\hline
\end{tabular}

\section{Discussion}

During the past half-century, organ transplantation has been considered as an effective treatment for end-organ damage. Such procedures have resulted in higher quality of life and longevity of tens of thousands of patients with end-organ damage, and demand for organ transplantation has been on the rise ever since. However, the number of available transplanted organs does not correspond with the demand, and an organ shortage crisis has been a major 
concern worldwide. This problem is more prevalent in developing countries where patients with end-organ damage are in more critical condition $(11,12)$. Cadaveric organ donation in the Eastern Mediterranean region is less common compared with European countries, the United States, and the Western Pacific (13). Factors such as unbalanced distribution of healthcare facilities, lack of priority of prevention over treatment, poor governmental support of organ transplantation, inadequate knowledge of the medical community and public awareness regarding organ donation, and lack of medical team cooperation are among the shared features of the countries located in the Eastern Mediterranean $(14,15)$. Countries such as Iran, Turkey, Saudi Arabia, Kuwait, Tunisia, Jordan, and Lebanon have consistent, active medical programs in the field of cadaveric donation of different organs, including the liver, heart, pancreas, and lungs. Higher per capita income in these developing countries is the main reason for the rising trend of organ donation and transplantation. However, most of these countries are faced with the disproportionate rate of available donor organs to the current demand $(10,15,16)$. According to our findings, the number of cases referred to organ transplant centers (i.e., patients with brain death per year) was not significantly different during the course of the study. Due to the lack of reliable statistics regarding the total number of diagnosed brain deaths during our research, the percentage of referred cases to organ procurement units could not be determined. Similar studies performed in Iran, Philippines, Germany, and Singapore have reported no significant changes in the number of referrals to organ procurement units with diagnosed brain death (17-21). In this regard, the rate of referred cases with brain death to organ procurement units has been reported to range between $63.8 \%-93.6 \%$ in European countries. For instance, this rate has been reported to be $90 \%$ in Belgium and $63.8 \%$ in Sweden. In Belgium, the total number of potential organ donors increased from 289 cases in 1990 to 640 cases in 2013 (22). Considering the development of organ procurement and transplant networks in the region, the number of brain death diagnoses was expected to increase during the course of the current study. Lack of development in this regard could be attributed to the inadequate knowledge of nurses, physicians, and healthcare personnel about brain death and organ donation (22-24). During the course of the present study, the number of suitable organ donors was observed to increase due to the older age and use of "marginal" donors. Use of marginal donors for organ transplantation in our study was similar to that of other countries in the world. According to our findings, the ratio of appropriate organ transplantation from patients with brain death was $52.8 \%$. Although the number of cases against organ donation was relatively unchanged, rate of consent to organ donation increased from $34.8 \%$ in 2006 to $69.2 \%$ in 2013 . According to similar studies in Iran, rate of organ donation has significantly increased within the past decade $(19,25-27)$. Furthermore, higher satisfaction with organ donation in Iran could be attributed to the rising number of organ procurement units and enhanced public knowledge about this medical procedure (8). In the current research, mean age of the patients with brain death was $30.15 \pm 16.504$ years, which increased from $17.35 \pm 29.42$ years in 2006 to $17.14 \pm 32.30$ years in 2013. This is consistent with the findings of similar studies in the world, which have highlighted the increasing mean age of organ donors $(20,25,27,30-33)$. Increased age of patients with brain death could be attributed to the variable causes of this condition $(8,28,29)$, the most important of which are severe head trauma (65.5\%), cerebrovascular accident, brain tumors, and anoxia. This is in line with the results of similar studies in this regard $(19,25,33)$. According to statistics, rate of brain deaths due to head trauma has declined from $70 \%$ in 2006 to $57 \%$ in 2013 . This could be due to several factors, such as the reduced rate of road traffic accidents, enhancement of immediate medical care, and higher awareness of drivers, which have resulted in the lower rate of traumatic brain injury leading to brain death (34). This finding has been confirmed in previous studies $(25,27,33)$.

In the present study, $56.1 \%$ of the patients with consent to organ donation were Shia (official state religion in Iran), while $10.6 \%$ were non-Shia. On the other hand, the main reason for refusal of organ donation in non-Shia individuals was disagreement for donating organs to individuals of other religious backgrounds. This finding could be explained through considering the effect of ethnicity on the intention for organ donation (35). In the current study, we also investigated the causes of disagreement with organ donation in the families of patients with brain death. In most of the cases, families were reluctant to mention their reasons for disagreement $(42.2 \%)$, which could be due to the inadequate knowledge or unsettling mental state of the family at the time of the survey. The most common reason for the refusal of organ donation was the denial of brain damage as the actual death of the patient. Moreover, believing in miracles was reported as another cause of disagreement with harvesting the organs of brain dead patients. In general, the families of patients with brain death believed that the condition could be reversed either through medical interventions or by a miracle. Previous studies have investigated the causes of agreement or refusal of organ donation reporting similar results (denial of the death of patient and believing in miracles in families) (19). In the present study, we evaluated the reasons for the disagreement of the relatives of brain dead patients with organ donation. According to our findings, most of the disagreements came from the mother of the patient (15\% of all the cases), which denotes the significance of emotional factors in the process of organ donation. Analysis of the collected data indicated that rate of maternal opposition decreased during the course of our study 
(from $15.6 \%$ in 2006 to $3.1 \%$ in 2013). This finding is indicative of the improved performance of coordinating teams in dealing with the families of patients with brain death in healthcare facilities.

\section{Conclusions}

According to the results of the current research, denial of brain death was the most important cause of disagreement with organ donation, the rate of which had no significant difference during the course of the study. Uniformity of the attitudes of society members toward organ donation could be a sign of the inefficacy of the mass media, as the most essential sources of information, in raising social awareness about organ donation. It is recommended that diagnosis rate of brain death and medical criteria for organ donation had no significant difference during the course of the present study. However, compared with the first year of the research, the number of donor organs increased more than twofold at the end of the experiment. Considering the mortality patterns in developing countries, such as Iran and other Mediterranean regions, enhancement of medical services and accurate identification of cases with brain death could eliminate the need for organ donation from living donors or after cardiac death.

\section{Acknowledgments:}

We would like to thank all people who participate in this study, especially Mrs. Lida Jarahi and Mashhad University of Medical Sciences.

\section{Conflict of Interest:}

There is no conflict of interest to be declared.

\section{Authors' contributions:}

All authors contributed to this project and article equally. All authors read and approved the final manuscript.

\section{References:}

1) Abouna GM. Organ shortage crisis: problems and possible solutions. Transplant Proc. 2008; 40(1): 34-8. doi: 10.1016/j.transproceed.2007.11.067. PMID: 18261540 .

2) Morris PJ. Transplantation--a medical miracle of the 20th century. N Engl J Med. 2004; 351(26): 2678-80. doi: 10.1056/NEJMp048256. PMID: 15616201.

3) Matesanz R, Mahillo B, Alvarez M, Carmona M. Global observatory and database on donation and transplantation: world overview on transplantation activities. Transplant Proc. 2009; 41(6): 2297-301. doi: 10.1016/j.transproceed.2009.05.004. PMID: 19715901.

4) Pomfret EA, Sung RS, Allan J, Kinkhabwala M, Melancon JK, Roberts JP. Solving the organ shortage crisis: the 7th annual American Society of Transplant Surgeons' State-of-the-Art Winter Symposium. Am J Transplant. 2008; 8(4): 745-52. doi: 10.1111/j.1600-6143.2007.02146.x. PMID: 18261169.

5) Backer H, Piros L, Langer RM. Increasing living donor kidney transplantation numbers in Budapest. Transplant Proc. 2013; 45(10): 3678-81. doi: 10.1016/j.transproceed.2013.10.001. PMID: 24314995.

6) Al Sebayel M, Alenazi AM, Sabbagh R, Al Ageel T, Al Enazi M, Al Bahili H, et al. Donor organ shortage crisis: a case study review of a financial incentive-based system. Transplant Proc. 2014; 46(6): 2030-5. doi: 10.1016/j.transproceed.2014.06.024. PMID: 25131100.

7) Mahillo B, Carmona M, Alvarez M, White S, Noel L, Matesanz R. 2009 global data in organ donation and transplantation: activities, laws, and organization. Transplantation. 2011; 92(10): 1069-74. doi: 10.1097/TP.0b013e31823360b1. PMID: 22005777.

8) Gomez MP, Perez B, Manyalich M. International Registry in Organ Donation and Transplantation. Transplant Proc. 2014; 46(4): 1044-8. doi: 10.1016/j.transproceed.2013.11.138.

9) Ghods AJ. Renal transplantation in Iran. Nephrol Dial Transplant. 2002; 17(2): 222-8. doi: 10.1093/ndt/17.2.222. PMID: 11812870.

10) Ghods AJ. The history of organ donation and transplantation in Iran. Expe Clin Transplant. 2014; 12 Suppl 1: 38-41. doi: 10.6002/ect.25Liver.L29. PMID: 24635790.

11) Aubrey P, Arber S, Tyler M. The organ donor crisis: the missed organ donor potential from the accident and emergency departments. Transplant Proc. 2008; 40(4): 1008-11. doi: 10.1016/j.transproceed.2008.03.059. PMID: 18555101.

12) White SL, Chadban SJ, Jan S, Chapman JR, Cass A. How can we achieve global equity in provision of renal replacement therapy? Bull World Health Organ. 2008; 86(3): 229-37. doi: 10.2471/BLT.07.041715 PMID: 18368211, PMCID: PMC2647401. 
13) Mahillo B, Carmona M, Álvarez M, Noel L, Matesanz R. Global Database on Donation and Transplantation: goals, methods and critical issues (www.transplant-observatory.org). Transplantat Rev. 2013; 27(2): 57-60. doi: 10.1016/j.trre.2013.01.001. PMID: 23477800.

14) Shaheen FA, Souqiyyeh MZ. How to improve organ donation in the MESOT countries. Ann Transplant. 2004; 9(1): 19-21. PMID: 15478882.

15) Shaheen FA, Souqiyyeh MZ, Ramprassad K, Attar MB. Current issues and problems of transplantation in the Middle East: the Arabian Gulf. Transplant Proc. 2001; 33(5): 2621-2. PMID: 11498091.

16) Lo CM. Deceased donation in Asia: challenges and opportunities. Liver Transplant. 2012; 18 Suppl 2: S57. doi: 10.1002/lt.23545. PMID: 22961949.

17) Suguitan GA, Cabanayan-Casasola CB, Danguilan RA, Jaro JM. Outcome of referrals for deceased organ donation to the government organ procurement organization. Transplant Proc. 2014; 46(4): 1074-6. doi: 10.1016/j.transproceed.2014.01.005. PMID: 24815132.

18) Mizraji R, Perez S, Alvarez I. Brain death: epidemiology and quality control of solid organ donor generation. Transplant Proc. 2004; 36(6): 1641-4. doi: 10.1016/j.transproceed.2004.06.066. PMID: 15350439.

19) Mahdavi-Mazdeh M, Khodadadi A, Tirgar N, Riazi N. Rate of family refusal of organ donation in deadbrain donors: the Iranian tissue bank experience. Int J Organ Transplant Med. 2013; 4(2): 72-6. PMID: 25013656, PMCID: PMC4089313.

20) Kwek TK, Lew TW, Tan HL, Kong S. The transplantable organ shortage in Singapore: has implementation of presumed consent to organ donation made a difference? Ann Acad Med Singapore. 2009; 38(4): 346-8. PMID: 19434338.

21) Fischer - Fröhlich CL. Factors limiting organ donation in Baden - Württemberg. Clin Transplant. 2013; 27 Suppl 25: 1-5. doi: 10.1111/ctr.12157. PMID: 23909496.

22) Roels L, Spaight C, Smits J, Cohen B. Donation patterns in four European countries: data from the donor action database. Transplantation. 2008; 86(12): 1738-43. doi: 10.1097/TP.0b013e3181908e08. PMID: 19104414.

23) Shirley S, Cutler J, Heymann C, Hart M. Narrowing the organ donation gap: hospital development methods that maximize hospital donation potential. J Heart Lung Transplant. 1994; 13(5): 817-23. PMID: 7803422.

24) Kosieradzki M, Jakubowska-Winecka A, Feliksiak M, Kawalec I, Zawilinska E, Danielewicz R, et al. Attitude of healthcare professionals: a major limiting factor in organ donation from brain-dead donors. J Transplant. 2014; 2014: 6. doi: 10.1155/2014/296912.

25) Khoddami Vishteh HR, Ghorbani F, Ghobadi O, Shafaghi Sh, Barbati ME, Rostami Louyeh A, et al. Causes and follow-up outcomes of brain dead patients in Shahid Beheshti University of Medical Sciences hospitals. Pajoohandeh J. 2010; 15(4): 171-8.

26) Kazemeyni SM, Sorosh AR, Afzali A. Organ yield from deceased donors: initial experience of an organ procurement unit in Iran. Arch Iran Med. 2009; 12(2): 170-2. PMID: 19249888.

27) Hajyhosseinloo M, Eftekhari A, Gorbani S, Zarei Z. Study of Brain Death and Organ Donation in West Azerbaijan Province (2004-2010). Iran J Forensic Med. 2011; 3(17): 149-56.

28) Capron AM. Six decades of organ donation and the challenges that shifting the United States to a market system would create around the world. Law Contemp Probs. 2014; 77: 25.

29) Desschans B, Evrard P. Organ donation and transplantation statistics in Belgium for 2012 and 2013. Transplant Proc. 2014; 46(9): 3124-6. doi: 10.1016/j.transproceed.2014.09.170. PMID: 25420841.

30) Fisher A, Herzog LJ, Herzog EM. Five years' experience of an organ donation team in southern Israel. Israel J Med Sci. 1996; 32(11): 1112-9. PMID: 8960085.

31) Tenn-Lyn NA, Doig CJ, Shemie SD, Teitelbaum J, Cass DE. Potential organ donors referred to Ontario neurosurgical centres. Can J Anaesth. 2006; 53(7): 732-6. doi: 10.1007/BF03021634. PMID: 16803923.

32) Nozary Heshmati B, Tavakoli SA, Mahdavi-Mazdeh M, Zahra S. Assessment of brain death of organ donors in Iran. Transpl Internat. 2010; 23(5): e7-9. doi: 10.1111/j.1432-2277.2010.01060.x.

33) Hajyhosseinloo M, Eftekhari A, Gorbani S, Zarei A. Study of Brain Death and Organ Donation in West Azerbaijan Province (2004-2010). IJFM. 2011; 17(3): 149-55.

34) Abbasi Z, Peyman A. Brain death and organ donation in Iran. Iran J Med Law. 2012; 6(20): 43-54.

35) Bendorf A, Pussell BA, Kelly PJ, Kerridge IH. Socioeconomic, demographic and policy comparisons of living and deceased kidney transplantation rates across 53 countries. Nephrology (Carlton). 2013; 18(9): 633-40. doi: 10.1111/nep.12101. PMID: 23692370. 